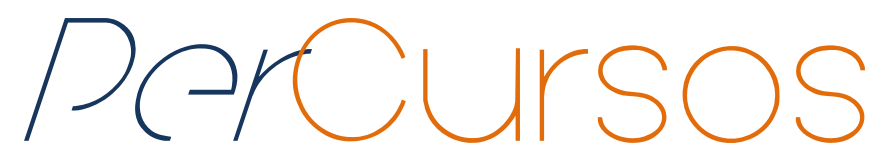

\title{
Uma mulher e algumas histórias: a sedução em Antonio Larreta, Milton Schinca e Juan Manuel Blanes - entre a tela e o verbo
}

\section{Resumo}

No último quartel do século XIX, um pintor uruguaio retrata com seus pincéis, a imagem de uma imponente dama. Vestida de branco e cercada por flores generosamente distribuídas, possui a boca entreaberta e as narinas dilatadas como que no ímpeto da aspiração iniciar a narrativa de sua história. Sabe-se, no entanto, que por trás dos arranjos florais, nos bastidores da imagem, subjazem os personagens que protagonizaram um conturbado drama. Ele: Juan Manuel Blanes, um reconhecido pintor uruguaio. Ela: Carlota Ferreira, cujas representações ambíguas oscilam entre a imagem da mulher oportunista de fama dúbia, e a da moderna transgressora e irreparável avant la lettre. Do encontro entre Carlota e Blanes nasce um controverso enredo de intrigas que culmina num desfecho trágico. O presente artigo analisa as representações literárias do encontro entre a musa e o pintor, delineados por dois autores uruguaios: Milton Schinca e Antonio Larreta. Pretende-se, desta forma, confrontar as narrativas com a sedução e o erotismo presentes em obras e cartas de Juan Manuel Blanes.

Palavras-chave: Retratos; Ferreira, Carlota, 1838-1912; Blanes, Juan Manuel, 1830-1901; Larreta, Antonio, 1922-2015; Schinca, Milton, 1926-2012.

\author{
Marlen De Martino' \\ Doutora em Artes Visuais pela \\ Universidade Federal do Rio \\ Grande do Sul - UFRGS e Alanus \\ Hochschule für Kunst - Köln - \\ Alemanha. Professora da \\ Universidade Federal do Rio \\ Grande - FURG/RS. \\ Brasil \\ demartino.marlen@gmail.com
}

\footnotetext{
${ }^{1}$ Agradeço a Dona Socorro Moreira, do Archivo General de la Nacion, em Montevidéu, por ter me recebido e atendido às minhas solicitações de modo tão polido e gentil.
} 


\title{
A woman and some stories: seduction in Antonio Larreta, Milton Schinca and Juan Manuel Blanes - between the literary and artistic
}

\begin{abstract}
In the last quarter of the nineteenth century, a Uruguayan painter depicts with his brushes, the image of an imposing lady. Dressed in white and surrounded by flowers generously distributed, she has a half-open mouth and dilated nostrils, as if, at the momentum of aspiration, began the narrative of her history. It is known however that behind the floral arrangements, at the backstage of the image, emerge the characters who staged a historical drama. He: Juan Manuel Blanes, a prominent Uruguayan painter. She: Carlota Ferreira, whose ambiguous representations oscillate between the image of opportunistic woman of dubious reputation, and the modern transgressive and irreparable avant la lettre. From the meeting between Carlota and Blanes had born a controversial plot of intrigue that culminates in a tragic outcome. This article analyzes the literary representations of the encounter between the muse and the painter delineated by two Uruguayan authors: Milton Schinca and Antonio Larreta. It is intended in this way confront the narratives with seduction and eroticism present in works and letters of Juan Manuel Blanes.
\end{abstract}

Keywords: Portraits; Ferreira, Carlota, 1838-1912; Blanes, Juan Manuel, 1830-1901; Larreta, Antonio, 1922-2015; Schinca, Milton, 1926-2012.

\section{Para citar este artigo:}

DE MARTINO, Marlen. Uma mulher e algumas histórias: a sedução em Antonio Larreta, Milton Schinca e Juan Manuel Blanes - entre a tela e o verbo. Revista PerCursos, Florianópolis, v. 17, n.33, p. 32 - 54, jan./abr. 2016.

\section{DOI: 10.5965/1984724617332016032}

http://dx.doi.org/10.5965/1984724617332016032 
O bioma geográfico e cultural representado pelas planícies do pampa foi tematizado incansavelmente por Juan Manuel Blanes ${ }^{2}$. O pintor uruguaio capitaneou esforços para construir uma pintura que privilegiasse questões pertinentes à América do Sul e retratasse não apenas temas religiosos, mitológicos e históricos pertinentes à Europa, mas que apresentasse os assuntos peculiares à paisagem cultural sul-americana. Interessou-se em pintar o homem que habitava a América meridional, expondo seu tipo físico, os trajes característicos e a natureza desértica dessas paragens. Blanes foi responsável por iniciar alunos no universo artístico nas duas margens do rio da Prata. As telas baseadas em episódios históricos o configuraram como um pintor americanista, adjetivação que costumava empregar em suas cartas para se referir ao seu trabalho. Esse termo se deve ao fato de Blanes retratar uma história da América entre Chile, Paraguai e a banda oriental. No entanto nesse ensaio não abordaremos essa faceta do pintor. Falaremos das mulheres pintadas pelo maestro a partir das implicações literárias e artísticas desses retratos na literatura uruguaia, de modo a tecer aproximações entre ambas.

Na Banda Oriental do Uruguai, o ano é 1876. Neste período Juan Manuel Blanes dedica-se arduamente à tela El Juramento de los treinta y tres orientales, executada entre 1875 e 1877 que the conferiria renome histórico. Concomitante a esta pintura realiza o retrato de sua esposa Maria Linari. Ao retratá-la denuncia um olhar lânguido e melancólico com uma ternura distante, cujo objeto parece não ser o espectador e sim uma terra remota, quem sabe a sua Itália natal. Não há a exuberância no cenário, a riqueza da tela parece despontar a partir do olhar doce e triste de sua esposa Maria, cuja imagem suspeita-se ser a contraposição da personagem Carlota Ferreira pintada por ele, anos depois. Maria não desafia a tela. Parece permitir ser observada, como se não houvesse escolha ou como se a sensação de ser espreitada não fosse relevante para ela.

\footnotetext{
${ }^{2}$ As iconografias pertinentes à obra do pintor Juan Manuel Blanes são aprofundadas brilhantemente na tese de doutorado de Fábio Feltrin de Souza: Extremidades da nação: violência, biopolítica e anti-modernidade no discurso fundacional da Argentina, defendida na Universidade Federal de Santa Catarina, no ano de 2011.
} 


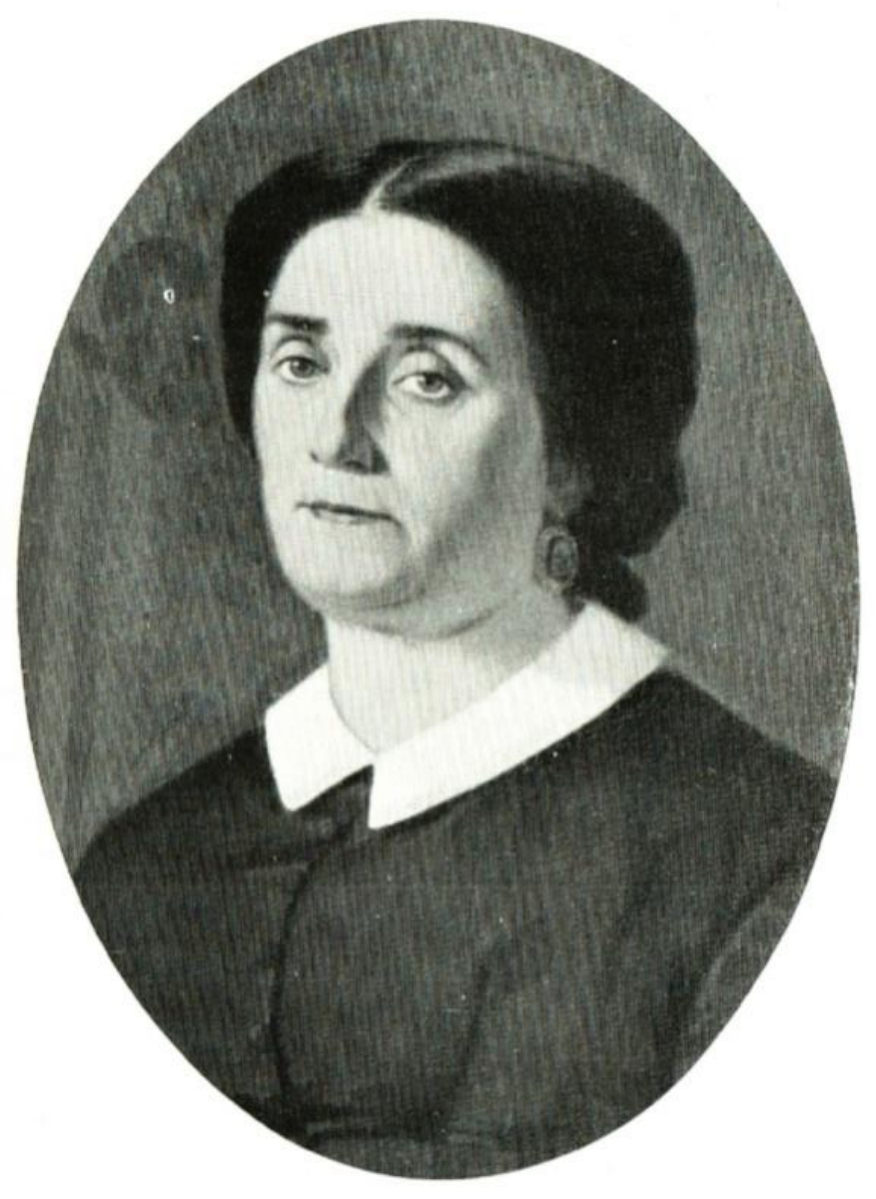

Juan Manuel Blanes. Maria Linari. 1879, óleo sobre tela. 0,75 x 0,61.

O azul celeste dos olhos de Maria Linari irradia a atitude de contemplação, típica das pinturas do século XIX, incansáveis em repetir personagens dispostos em cenas sociais, mas cujo olhar revela toda uma gramática da solidão. Frequentemente as pessoas representadas nessas telas possuem em comum, um vítreo e distante olhar revelando um pensamento aquém, ora vazio, ora em desamparo. O sujeito pintado então pareceria não poder ser apreendido ou capturado. Seus pensamentos encontram-se vedados ao outro... Quando os retratos retumbam nas salas aristocráticas do fin-de-siècle, surge de forma cada vez mais impetuosa a impossibilidade da presença. As pistas dessa ausência, entretanto podem ser sentidas através de uma sofisticação candente em relação aos rastros de presença que acompanham os retratos femininos do período, afinal elementos florais tomam lugar na composição, sugerindo as pistas que poderiam ser deixadas pelas mulheres com suas flores e perfumes. No retrato de Maria Linari, não há flores, o fundo é pleno e escuro, o que brilha na tela é a evasão de sua mirada. Não é por acaso que a vida 
íntima do pintor uruguaio tenha servido de manancial para a literatura e o teatro uruguaio contemporâneo. Há toda uma tragédia que percorre a vida de Blanes, omitida frequentemente por pesquisadores receosos em expor os episódios biográficos. Eximemse da pecha de comentadores domésticos que arranhariam as telas ao conceder traços biográficos sensacionalistas e redutores da obra. O fato é que a literatura e o teatro não se fizeram de rogados e ao invés de esterilizar a arte com o intuito de dignificá-la, com uma atmosfera pretensamente séria e científica, apropriaram-se da vida do pintor e de seus retratos tingindo-os com outras tonalidades.

Os anos entre 1883 e 1885 foram prolíficos para as telas de Blanes dado que seus retratos mais famosos como Artigas na cidadela, de 1884, fora executado a partir de desenhos do general já idoso. Blanes o remoça e concede uma feição de orgulho uruguaio tão popular que suas réplicas e cópias podem ser encontradas em diversos guichês alfandegários, nas fronteiras do país. Os retratos pintados por Blanes apresentam personalidades relevantes para a história do Uruguai interessadas em investir na construção de sua imagem; além do mais, a encomenda de uma pintura exigia que os compradores possuíssem capital, pois demandava consideráveis recursos para que fosse executada. Entretanto, ao caminharmos pelas galerias onde tais imagens são enfileiradas, frequentemente a história das pessoas parece obliterada pelo tempo e nem ao menos uma nota acerca da atividade ou interesse do retratado é incluída. Ficam apenas os gestos das mãos, as características da vestimenta ou a expressão facial para imaginarmos o que estaria escrito no obituário, no dia em que aquela pessoa faleceu. 


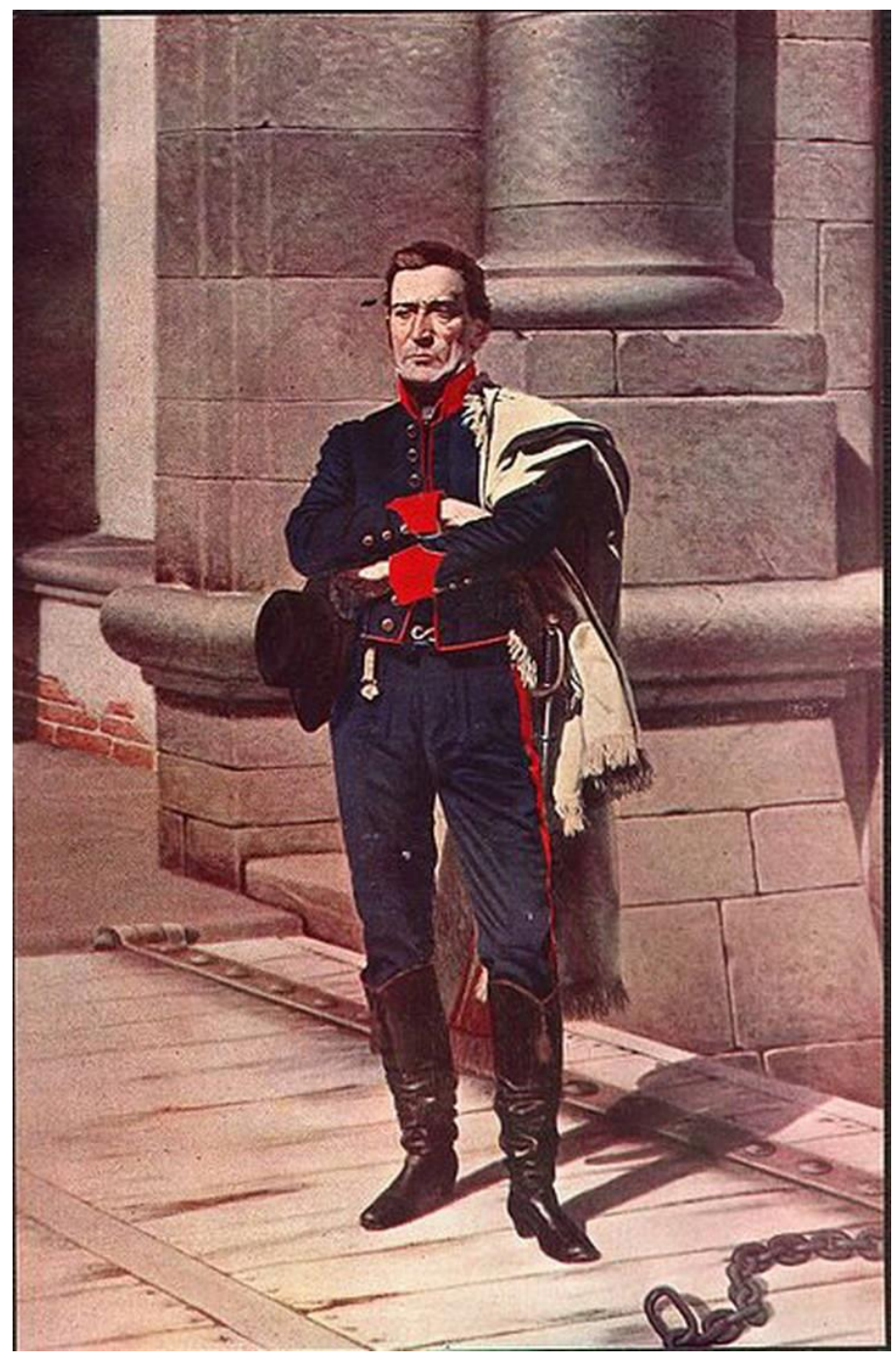

Juan Manuel Blanes. Artigas na cidadela. 1884, óleo sobre tela. Museu Histórico Nacional, Montevidéu.

No retrato de Maria Linari avista-se uma história. Anos antes, em 1854, a jovem italiana Maria, era casada com Omero Cappello, entretanto, apaixona-se pelo pintor uruguaio. Ambos fogem e são impossibilitados de oficializar a união, contraindo matrimônio anos depois, quando o antigo marido viera finalmente a falecer. Maria tem com o pintor, dois filhos: Juan Luís e Nicanor que, futuramente, aprenderiam com o maestro todos os rudimentos da pintura sendo enviados à Europa para aprimorar suas habilidades artísticas em Veneza e Florença. Apesar da peripécia amorosa vivenciada na juventude por Maria e Blanes, o pintor prefere retratá-la desprovida de jovialidade, adornos e cores representando-a com a sobriedade e a candura de uma mãe bondosa. 
Entretanto, esses adjetivos não seriam os primeiros a vir à mente ao se deparar com o quadro que Blanes pinta de Dona Isabel Chilavert de Blanes, sua mãe. Antes de partimos para a obra de arte basilar para a escrita desse texto, acreditamos ser relevante perceber as tonalidades expressivas que Blanes emprega para caracterizar as mulheres que exerceram um vigoroso impacto em sua vida, apontando o parentesco entre a série de cartas escritas pelo autor e suas pinturas. No quadro de Dona Isabel, com a qual o pintor mantinha fortes laços de admiração, é possível perceber o olhar de uma mulher que apesar de apresentar em sua face, os traços de uma idade avançada, ainda assim ergue uma de suas sobrancelhas e enfrenta o espectador com um olhar altivo e confiante, sem resignação. A abordagem parece bem distinta daquela empregada para retratar a doçura de Linari. Na carta da mãe para Blanes, em 1864, ela escreve ternamente sobre a saudade que sente do filho e de sua família, chamando-o com o diminutivo carinhoso de uma mãe. Apenas para ela, ele não era o maestro mas seu Juanito. No ano de 1915, ao examinar o quadro de sua mãe, descobre-se que o pintor havia guardado a carta junto da tela que representava o rosto da mãe. (LAROCHE Apud SALTERAIN y HERRERA p. 105). O gesto parece demonstrar um ato secreto de amor e devoção. Portanto, é relevante ressaltar a curiosa relação de Blanes no que tange a pintura e o verbo. 


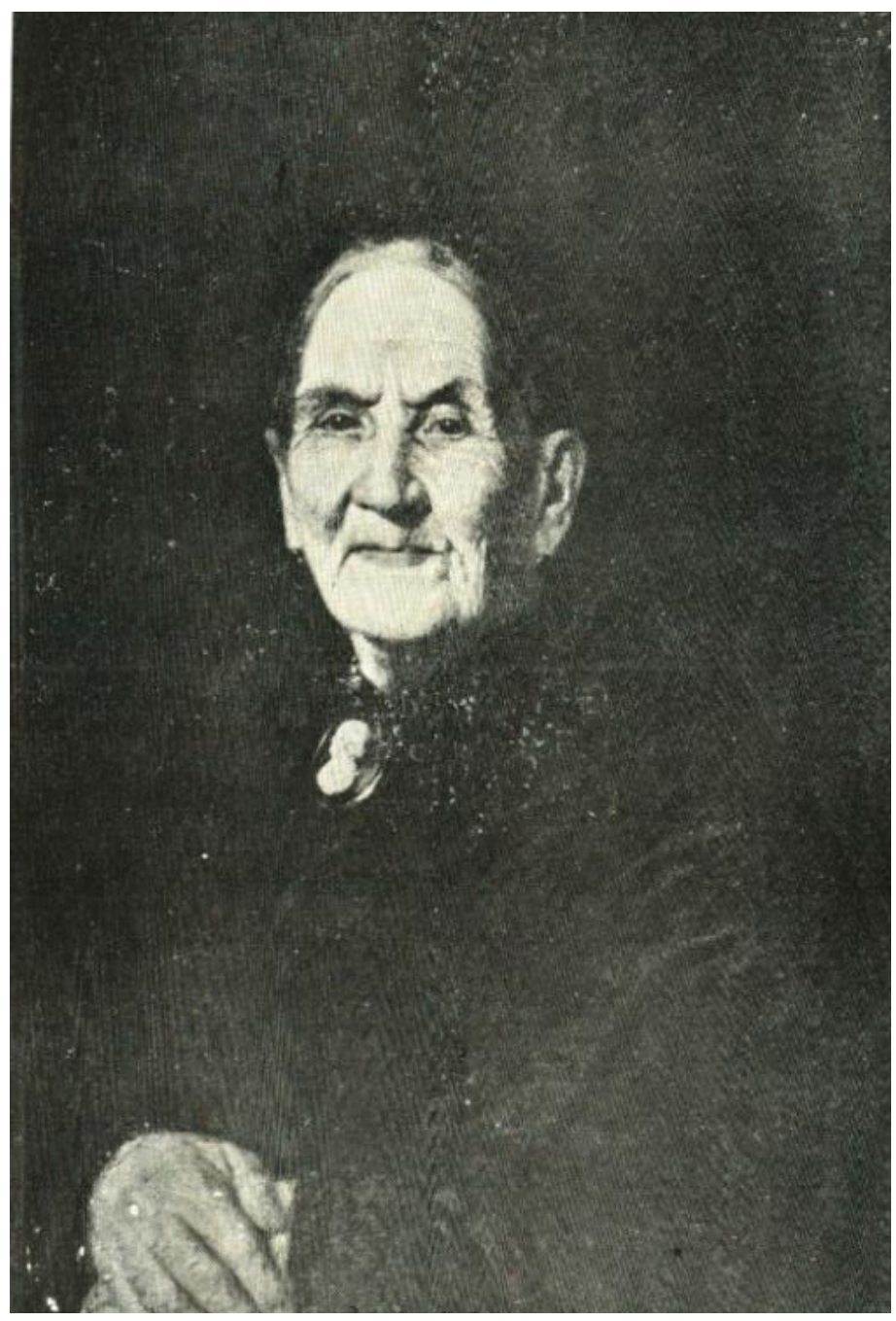

Juan Manuel Blanes. Retrato de sua mãe. (Ano desconhecido), óleo sobre tela. Museu de Artes Visuais, Montevidéu.

Em 1883, um ano antes da pintura dedicada ao general Artigas e sete anos após pintar Maria Linari, emerge outro retrato que ocuparia um importante lugar na memória popular do país. Surge na tela, uma mulher impávida e enigmática, marcada pelos excessos e transgressões, diante dos interditos sociais que ousara burlar. Seu nome: Carlota Ferreira. Ao pintá-la, uma perspectiva totalmente distinta é adotada para denunciar a personalidade da retratada. Diferente dos retratos cujo rosto figura como principal elemento, Blanes prefere expor o corpo de Carlota ladeado por camélias ao fundo e rosas maduras esbranquiçadas em seu decote. Todo um inventário de aromas atinge o espectador. Sabe-se que o pintor nem ao menos suspeitava dos acontecimentos funestos que o levariam a vivenciar um tumultuoso drama familiar, mas poderíamos 
pensar que a flor bordada no xale despejado na cadeira seria também uma antecipação dos futuros episódios, visto que as rosas em inúmeros manuais sobre a linguagem das flores é associada ao amor enquanto a malva à ambição.

No ano de 2002, o escritor, crítico e teatrólogo uruguaio, Antonio Larreta escreve o livro $O$ guante no qual recria o famoso caso entre Carlota e Blanes. O romance é situado em Montevidéu e nas constantes viagens realizadas por Blanes e sua família à Europa. $O$ autor explora a passagem de Carlota Ferreira na vida da família ao narrar a forma marcante com que vai movimentar a vida de cada um dos personagens da trama. Outro aspecto a ser levado em consideração é a inserção no romance, do pintor catalão e personalidade histórica, Mariano Fortuny. Apesar de não haver comprovação da amizade entre Mariano Fortuny e Juan Manuel Blanes a partir de uma licença poética, Larreta cria a amizade entre os dois, ao expor também o relacionamento entre seus filhos. Desse modo, Larreta concede à ficção um viés intrincado no qual Carlota Ferreira é um dos elementos da rede de sedução.

Larreta explora em diversos momentos de sua narrativa um repertório de aromas que invadem as cenas. A lembrança de Carlota Ferreira surge tanto para Blanes como para seu filho mais novo, Nicanor, acompanhada pelo cheiro almiscarado que a todos alcança, anunciando a sua presença e deixando-a mais fulgurante após sua saída. Em O guante há uma relação tecida entre Carlota e as óperas apresentadas em Montevidéu, como Aída, a etíope que morre por amor. O olor do Oriente se manifesta quando Blanes logo antes de falecer, parece rever a tela e começa: "a sentir el perfume de Carlota, mezcla de sudor y esencias exóticas" (LARRETA, 2002, p. 24). O filho mais novo de Blanes, Nicanor, apaixona-se por Carlota e casa-se com ela, em 1885, sem o consentimento da família. O matrimônio é anulado por ela que alega não tê-lo consumado, o que traz desgosto para a família por sentir-se duplamente enganada diante da pantomina. Larreta divide o livro em capítulos que concedem a percepção ora de Blanes, ora de Maria, ora de Nicanor, tecendo uma multifacetada narrativa. Os capítulos dedicados a Nicanor demonstram sua personalidade tímida, reflexiva, conturbada e sensível. Apaixonado por Carlota durante longo tempo ele a encontra em toda a paisagem, em todo o romance e em toda a ópera. Lê Nossa Senhora de Paris e recorda 
da amada. Intimamente parece realizar a comparação entre ele, Quasímodo e ela, Esmeralda; a mulher impossível: cigana, bela e exótica. Nas citações literárias e olfativas de Larreta, há a evocação do orientalismo presente no século XIX, tanto na escolha dos aromas como nas associações entre personagens. Apesar do escritor, conceber Carlota como uma relevante personalidade do período, ainda assim confere em seus adornos os elementos distintivos de um comportamento dado a exotismos. Os escritores que se referem a Carlota Ferreira insistem em descrever o seu perfume, algo que não o fazem com Maria Linari, sinal da relevância da pintura de Blanes para o imaginário. A perspectiva que aborda as relações entre a pintura e o aroma não é nova.

Milton Schinca, narra, no livro Mujeres desconocidas del pasado montevideano, como a compreensão dos aromas e flores é relevante para o período. Em um almanaque há a indicação do uso de perfumes em papéis e luvas cujo rastro denunciasse a marca da passagem da mulher, preferencialmente solteira: "Las mujeres solteras deben escoger com preferência el White-Rose(...) El Cris de Italia es el perfume de la ropa blanca. Los guantes y el papel de cartas quedan muy bien com La Piel de España" (SCHINCA, 1999, p. 68-69). Oriundas da tradição inglesa que remonta a Shakespeare ${ }^{3}$ e todo o vocabulário hermenêutico atrelado à linguagem das flores, rosas, camélias, margaridas e lírios possuem todo um significado no qual não apenas os olhares, como os aromas e buquês poderiam ser lidos como sinais das pretensões dos amantes. Presentear uma pretendente com um ramalhete não era um galanteio desprovido de intenções em que o cavalheiro era inclinado a eleger as flores mais belas ou frescas regido meramente pelo acaso. Havia todo um vocabulário aliado ao gesto, o qual os protagonistas do enredo da sedução estavam habituados a ler. Era esse olhar que tornava possível que amantes se comunicassem, através das flores, leques e ventarolas, usados para sinalizar suas intenções a partir de todo um gestual, na maneira como eram abertos, fechados ou guardados esboçavam os "sins" e os "nãos" das conquistas. Não há obviedade na sedução, pois ela é cifrada e as incompreensões também detêm um lugar especial nesse

\footnotetext{
${ }^{3}$ Em Hamlet, há a menção de Ofélia ao presentear Laertes e a rainha com rosmaninho, arruda e malmequer, evocando a lembrança de uma pureza perdida, devido a promessas não cumpridas. Quando a cena é pintada, principalmente pelos neo-rafaelitas, as flores são dispostas junto à Ofélia no momento de sua morte no rio.
} 
jogo. Apesar da necessidade de símbolos, ainda assim existe o indecifrável, o inatingível criado pela dúvida. E não é a dúvida que torna a sedução algo possível, mas o assombro diante da dúvida é que permite que a sedução seja também enigma.

Em 1974, o escritor e dramaturgo Milton Schinca realiza uma obra teatral intitulada Los Blanes. Um ano antes em 1973, Juan Maria Bordaberry, institui o golpe de estado que daria início ao longo e funesto período antidemocrático no qual a ditadura civil-militar uruguaia, alinhada aos governos autoritários de países como Brasil e Argentina, restringiu severamente a liberdade dos cidadãos ao cercear e violar os direitos humanos. A versão de Los Blanes foi, portanto, vetada pelos censores da Ditadura. Após modificações, em 1991 acaba por tornar-se um livro intitulado Nuestra Señora de los Ramos. Nesse livro é possível apontarmos uma íntima proximidade entre sedução e enigma a partir do diálogo entre Carlota e Blanes. Apenas no prólogo encontra-se a referência a Carlota e aos Blanes. No restante da obra, o autor prefere denominar os personagens como nomes como padre e hijo, dirigindo-se a Carlota como: Ella. Na discussão entre Ella (Carlota) e el padre (Blanes) lemos: “¡Esa capacidad suya de hacer irrumpir en el varón el desvario y el enigma en estado puro!... Desvarío, enigma: ¿conoces algo más?" (SCHINCA, 1991, p. 46). No retrato de Carlota Ferreira, Blanes permite que o observador escorregue o seu olhar no fundo da tela, desenhando através do movimento da retina uma coreografia pontuada por flores que permeiam cada pedaço de uma pintura que encontra o perfume e a transpiração da mulher. Carlota contempla o espectador, não com um olhar esquivo e fugidio, mas o encara confiantemente, de frente, com um misto de certeza e convocação. 


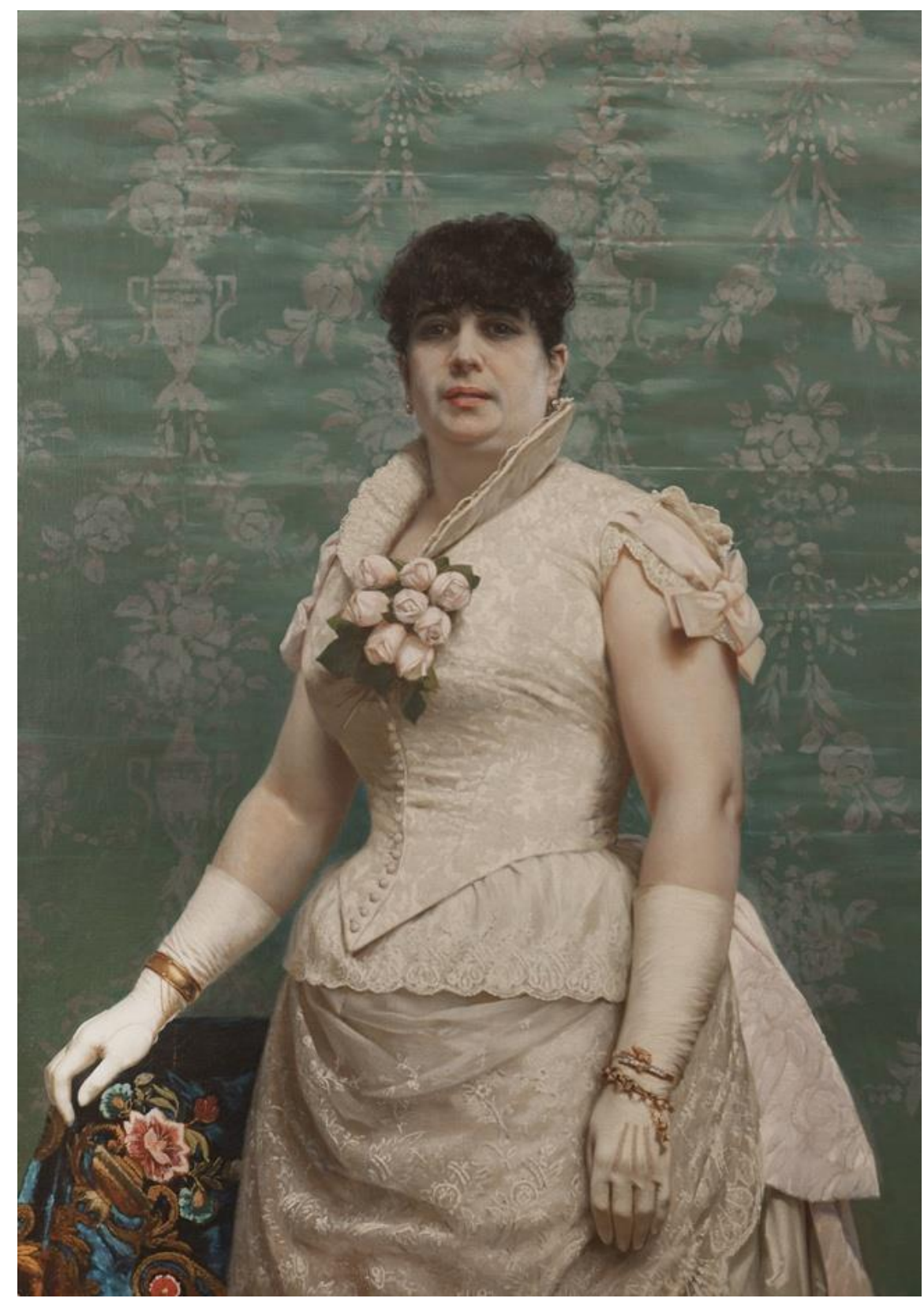

Juan Manuel Blanes. Retrato de Doña Carlota Ferreira de Regunaga. 1883, óleo sobre tela. 130 x $100 \mathrm{~cm}$. Museu de Artes Visuais, Montevidéu.

O episódio em que Carlota posa para Blanes é explorado em detalhes no livro de Larreta, porém o filho Nicanor acaba fazendo parte do retrato. Após uma das sessões nas quais Carlota serve de modelo e em que ela e pintor se relacionam, Blanes guarda as vestimentas e apetrechos para finalizar uma das mãos, aquela que repousa junto ao vestido. Solicita ao filho Nicanor que vista a luva. À medida que Nicanor cobre seus dedos com o adereço da mulher, sente-se dominado por ela, em um devir-musa no qual a luva é 
Carlota: "estaba invadido por Carlota, impregnado por ella. Cerró los ojos y era Carlota" (LARRETA, 2002, p. 67). As luvas, o vestido e o perfume apossam-se da lembrança de pai e filho. Na pose, no interior do ateliê, encontra-se um Nicanor transformado em Carlota. Esse artifício, utilizado pelo escritor não é o mesmo de Schinca cujos diálogos ocorrem nas salas de jantar e estar. O ateliê para Schinca é o local reservado para a última cena da peça, quando a tela será pintada.

Pode-se supor que o ateliê no século XIX, se apresentasse como um espaço heterotópico ao dispor de um dispositivo de funcionamento operatório distinto dos demais. Não apenas a luz, como as sensações seriam passíveis a todo tipo de modulação. De acordo com Corbin, ali, os corpos estariam dispostos entre vestidos e despidos "um lugar onde o status do personagem feminino e as posturas utilizadas se apresentam de forma tão complexa porque aí se misturam, conforme a necessidade, a artista, a modelo, a amante, a esposa" (CORBIN, 2009, p. 211). Neste recinto, habitualmente fechado aos olhares externos os artistas podiam estar alheios às perturbações advindas dos rumores externos. Após a pintura de seu retrato, Blanes ainda parece lembrar-se de sua modelo. Em uma de suas cartas, em Florença, pergunta a seu irmão Maurício: "Como la vá a D.

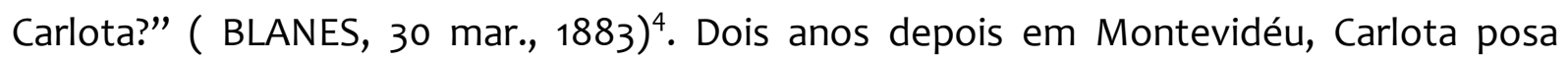
novamente para o pintor que realiza uma de suas mais polêmicas telas: Demônio, mundo e carne ${ }^{5}$. Ao contrário do retrato da senhora Carlota Ferreira que aparece com o corpo vestido e o rosto nu, o que se vê é justamente o contrário. A musa reclinada e enviesada jaz nua e recusa a oferecer o seu rosto ao espectador. Esconde sua face, quem sabe sem a intenção de ocultar a vergonha, mas por exigir o segredo da alcova. Carlota foi a musa de Blanes durante alguns anos e pode ter servido de referência para intuitivamente pintar olhares, gestos e corpos nas demais telas que realizou, pois o artista possui uma produção invejável.

\footnotetext{
${ }^{4}$ A correspondência de Juan Manuel Blanes mencionada nesse ensaio encontra-se no Archivo General de la Nacion em Montevidéu. Citamos especificamente três grupos de cartas localizadas na carpeta 2, Pieza 74, de 1855-1879; na carpeta 6, com cartas entre 1861 e 1893 e na carpeta 10 Pieza 59, com cartas que datam do período entre 1873-1902, último período da vida do pintor.

${ }^{5} \mathrm{O}$ título da obra é grafado de duas maneiras: Demônio, mundo e carne ou Mundo, demônio e carne. Esta última forma pode ser encontrada no livro de Eduardo de Salterain Y Herrera, publicado em 1950.
} 


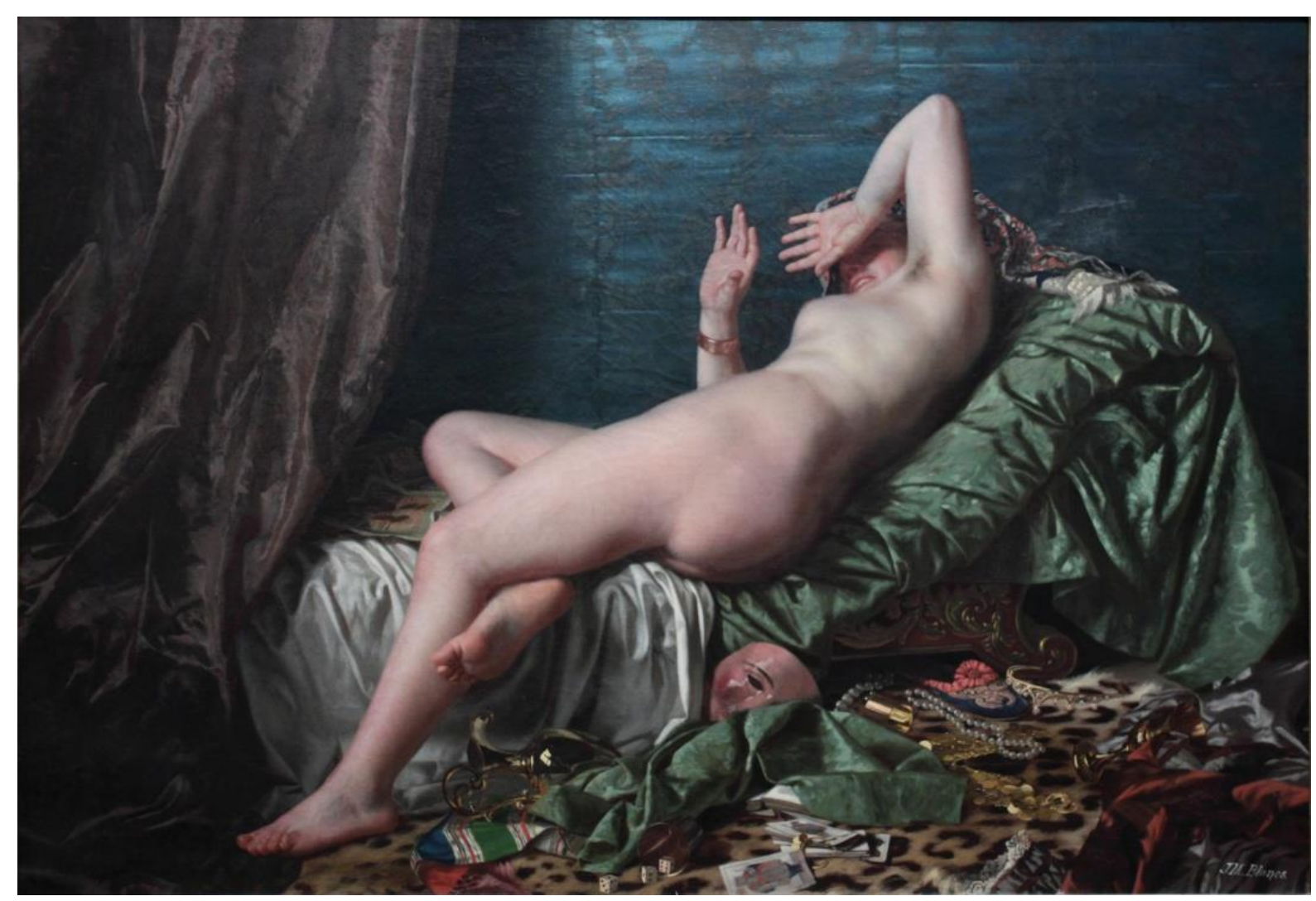

Juan Manuel Blanes. Demônio, mundo e carne. 1885, óleo sobre tela, 1,07x1,51 cm. Coleção Museu Nacional Juan Manuel Blanes, Montevidéu.

A menção às musas na história da arte detém um significado diverso. Desde os escritos de Hesíodo, tanto na Grécia como na Roma Antiga, são presenças fundamentais e suas imagens figuram dispostas ao lado dos grandes oradores e poetas. Apesar disso possuem um significado etéreo e fantasmático, sendo imagens condutoras do divino que cria. De acordo com Prose, a grande transformação em relação ao conceito de musa ocorre quando o cristianismo separa Eros e Ágape abrindo "um fosso profundo entre a arte religiosa e a secular. (...) Não havia mais deidades para tomar conta do lirismo, da canção de amor, da dança" (PROSE, 2004, p. 20). A mulher medieval desponta como a musa que surge em carne e osso, porém mesmo sem deter o estatuto etéreo que a consagrara anteriormente, agora ela é humana apesar de inacessível. As musas continuam mulheres belas e inatingíveis até surgir a mulher fatal, com sua acessibilidade malévola por não se recusar ao encontro.

O romance de Larreta narra a perplexidade do maestro, ao deparar-se atônito, diante da escultura de Rodin Danaide. A posição do corpo de Danaide provoca a 
lembrança do nu de Carlota disposto em Demônio, mundo e carne. Com um misto de desassossego perante o nu, em 1908, sete anos após a sua morte, a crítica em Montevidéu se expressa duramente diante do que considera a aspereza de Demônio, mundo e carne. Nesse mesmo ano, os uruguaios liam no jornal La Razón o comentário indignado: "Esa ausência total de carácter que se observa, _ decia el diário, _ em todos sus cadros (...) de una aridez extrema, exornada com retratos que no tienen más mérito artístico y psicológico que el muy discutible que resulta del parecido con el original” (n. 8695, 2 de abril de 1908, Montevidéu Apud SALTERAIN Y HERRERA, 1950, p. 232). Esta crítica, entretanto apresenta justificativas ambíguas, uma vez que resvalaria não só no clamor da cidade que antevê a mudança dos tempos como também em certo conservadorismo em relação ao um tipo de erotismo característico do século anterior. 0 final do século XIX reedita a figura da periculosidade feminina ${ }^{6}$, propondo um rico repertório de imagens que associa a mulher, à besta-fêmea e a nudez primordial, ávida pelos prazeres mundanos, os jogos de azar, as bebidas e o sexo. De acordo com a crença neoplatônica de que corpo e espírito seriam entidades antagônicas, os inimigos do espírito e do divino seriam três: o mundano, o demoníaco e a carne insensata: todos elementos presentes na mulher, amálgama máximo e incorporação dos perigos já apontados pelo manual inquisitório de Kramer e Spengler, que em um dos trechos propalam: "Toda bruxaria tem origem na cobiça carnal, insaciável nas mulheres. (...) Há três coisas insaciáveis, quatro mesmo que nunca dizem: Basta! A quarta é a boca do útero" (Kramer; Sprenger, 2009, p. 121). Diante do histórico que vincula mulher a pecado e a uma instintividade devastadora, está o personagem construído por Larreta, o filho de Blanes, Nicanor que apaixonado por Carlota se dirige ao armário do ateliê de seu pai e recupera o vestido branco do retrato. Neste instante: “uma vaharada e almizcle lo dejó verdaderamente boquiaberto, tal como si hubiera clavado un largo cuchillo em ele vientre

\footnotetext{
${ }^{6}$ Esse tema é explorado por Josefina Ludmer (2002), no livro O corpo do delito, quando se reporta ao estudo de Rebecca Stott acerca da fabricação vitoriana da mulher fatal. Ao mencionar o trabalho de Stott, afirma que a figura da femme fatale surge no último quartel do século XIX na Inglaterra, em um momento histórico no qual as mulheres ingressavam nos bancos universitários e em campos nunca antes imaginados. O termo francês surge no período de expansão imperial da Inglaterra, tanto na medicina, como na criminologia e na imprensa (STOTT, Rebecca. The fabrication of the late-victorian Femme Fatale. The kiss of death. Houndsmills, Basingstoke, Hampshire and London: The Macmillan Press, 1992 Apud Ludmer, 2002, p. 351).
} 
del bicho almizcarado." (LARRETA, 2002, p. 69.) Larreta aponta para um Nicanor cujo olhar torna Carlota um animal perfumado, perpetuando a dimensão concedida à mulher no XIX. Afinal, a Femme fatale é recorrentemente vinculada à besta, por isso nas telas do período há a pele de um animal caçado e abatido ao chão, sendo frequente a alusão aos pelos, ao vinho, a Baco, à serpente, à noite, elementos relacionados à maldição feminina, presentes em inúmeros quadros da época.

Em um dos trechos da peça Nuestra Señora de los Ramos o pai fala à mulher: “Hay algo monstruoso en vivir... Debemos apostar siempre em favor de los jugos, de los mediodías, del banquete del mundo; ;siempre!..." (SCHINCA, 1991, p. 60). Essa fala parece antever o quadro pintado mais tarde em que o banquete do mundo e os jogos seriam apresentados tendo a mulher como protagonista da perdição. Posteriormente, no século XX essa imagem da mulher fera, puro delírio, será manipulada cientificamente e um novo rótulo do demoníaco será impingido, havendo desta forma o advento da mulher histérica ${ }^{7}$. Ao analisar a tela Demônio, mundo e carne no artigo Juan Manuel Blanes e o gesto de perturbação do visível, a historiadora da arte Rosângela Cherem aproxima o quadro do pintor uruguaio às considerações acerca da carne da pintura, anunciando as relações entre a tela do uruguaio e A obra prima ignorada. Essa novela de Balzac, escrita em 1831 aborda "a imagem pictórica através da relação entre tela e pele" chamada por Didi-Huberman (2007), de acordo com Cherem, como uma “dramaturgia da encarnação". (CHEREM; MAKOWIECKY, 2010, p.41). A poética da pele como carne viva, cuja analogia seria a própria tela, estaria em Balzac e parece surgir na abordagem concedida à Carlota por Schinca que coloca em sua boca a seguinte sentença pronunciada a Blanes: "cada ser trae em su carne la llave de las cosas" (SCHINCA, 1991, p. 61).

O que esse ensaio propõe é destacar essa vertente associada ao erotismo cujas obras de Schinca e Larreta insistiram em ressaltar a partir de uma perspectiva biográfica. Blanes pinta a mulher fatal, uma Vênus sedutora, exemplificada pelo retrato de Carlota. Nada melhor, portanto, do que lançarmos mão da imagem da Afrodite ebúrnea de Filóstrato. Para o filósofo, a deusa era uma mulher madura e, por isso, a riqueza de sua

\footnotetext{
${ }^{7}$ Consultar: APPIGNANESI, Lisa. Tristes, loucas e más: a história das mulheres e seus médicos desde 1800. Rio de Janeiro: Record, 2011.
} 
beleza seria justamente essa: deter o encanto ainda que remanescessem as primeiras rugas. Embora a gravidade da maturidade despontasse, quem a contemplava conseguia aspirar nitidamente o que restava de sua juventude (FILÓSTRATO, 2012, p. 53). Parece ser esta a imagem que Blanes apresenta em sua tela. A beleza da maturidade que já se acentua evidenciando não o momento pueril quando a menina torna-se mulher, mas o período em que a mulher começa a se tornar anciã e ainda assim parece bela e sedutora. Não seria isso o que os deuses admirariam nos homens? A efemeridade concedida pelo tempo e que tornaria a beleza algo mais raro justamente por ser instantânea e fugaz?

Ao utilizarmos a observação de Filóstrato, poderíamos pensar que assim como a Vênus, Carlota começa a demonstrar o avanço da idade. As flores ao fundo e todas as demais ecoam em mesmo tom, exalando sem resignação, o último aroma dos anos pueris. Ao evocar em sua balada o retrato em flor da musa pintada, Charles Baudelaire canta o verso que poderia ser declamado ao contemplar o retrato de Doña Carlota: “onde as narinas móveis aspiram o desconhecido e o impossível, brilha, com inexprimível graça, o riso de uma grande boca vermelha e branca e deliciosa que faz sonhar o milagre de uma soberba flor que desabrocha em um terreno vulcânico" (BAUDELAIRE, 2006, p. 215).

Juan Manuel Blanes realiza viagens à Europa e detém um intenso envio de missivas principalmente para Maurício, seu irmão e confidente. No fim de sua vida, há em suas cartas a constante referência a um desânimo latente diante das dificuldades. É mister ressaltar o modo como Blanes se refere a seus infortúnios, ao utilizar exemplos oriundos da história da arte. Em nove de janeiro de 1891, pela terceira vez que cruza os mares em direção à Europa, escreve demonstrando cansaço e citando uma passagem da vida do Rei Davi: "Yo estoy um poco pateador ya, y no es fácil que duerma entre los nietos, _ trataré de dormir de outro modo, como el Santo Rey David, con arpa sin cordas" (BLANES, 9 jan, 1891). Sabemos que o vapor que partia da América do Sul rumo à Europa, efetuava paradas em algumas cidades, uma delas: o Rio de Janeiro. Em 1890, Blanes visita a cidade pela segunda vez, felicitando-se ao visitar o então Museu Imperial. Em maio de 1879 vê a tela de Pedro Américo, A batalha do Avaí. Blanes afirma ter ido ao Rio de Janeiro especialmente para ver a pintura. A bordo do França rumo à Europa decreta que o quadro é muito superior "ao outro", referindo-se às comparações realizadas entre a 
tela de Américo e a de Victor Meirelles que pinta a Passagem de Humaitá, entre 18681872, e a Batalha de Riachuelo, entre 1882 e 1883. Portanto, no trecho citado pelo pintor sobre o Rei Davi, podemos supor que Blanes também tenha visto a tela David e Abisag pintada por Pedro Américo, em 1879, já que ela encontrava-se no Museu naquele período. Na carta, parece realizar a alusão à tela de Américo cujo tema aborda não o fausto e as vitórias do rei Davi, mas seus anos finais. A história dos últimos anos de Davi pode ser encontrada em Romanos, quando o rei idoso sente muito frio. Seus súditos então procuram uma bela jovem por toda Israel. Encontram a sunamita Abisag que Ihe aquece gentilmente, mas como ressalta o livro, ele não a possui. A tela parece magistral justamente por pensar na conotação sexual do episódio. Ao vislumbrarmos a imagem, percebemos que enquanto Abisag entrega-se sem reservas ao rei, ele encontra-se impactado pelo assombro, lançando a lira ao chão. A corda solta parece demonstrar que o instrumento jaz intocável. No olho do leão, retrato do rei abatido, resta apenas a lembrança...

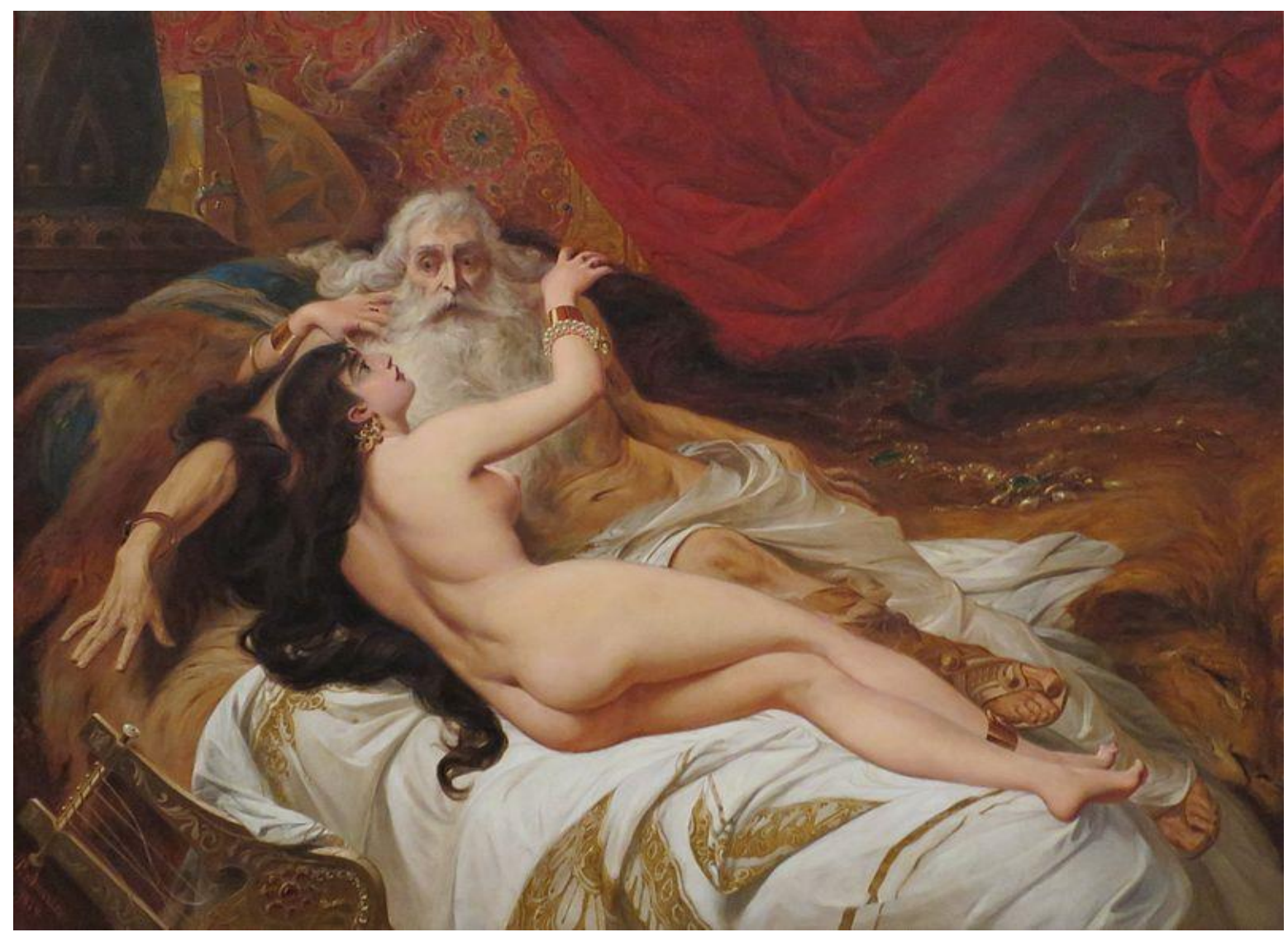

Pedro Américo. David e Abisag, 1879, óleo sobre tela, $172 \times 216 \mathrm{~cm}$. Museu Nacional de Belas Artes, Rio de Janeiro. 
É relevante perceber que a mulher fatal do século XIX pode figurar como um grande pesadelo, pois pode vir a produzir, o homem humilhado, desprovido da possibilidade de demonstrar a sexualidade requerida. Blanes cita o episódio bíblico exatamente da mesma forma em que é pintado por Américo. O curioso é atentar para as relações Américo e Blanes a partir da imagem do texto bíblico. Enquanto um o pinta, o outro se imagina como o personagem principal representado em sua velhice. Vê nas telas dos europeus a vanguarda que se instala e o modernismo, não sem insatisfação. Em carta ao seu irmão, Maurício, parece confessar o desconsolo de um pintor que sente a chegada das vanguardas artísticas aproximando-se ameaçadoramente. Blanes percebe-se como um ancião, um velho Davi.

O que essas obras nos mostram é que as recorrentes imagens do corpo feminino desnudo apresentam facetas em que a mulher ora é presa, ora é caçadora, ora opera em ambos os papéis. A questão posta é que a jovem amável e ingenuamente sedutora, como Abisag, ou mesmo a mulher fatal, aparece como elemento do desejo, como também do medo, pois o corpo dessa mulher pode proporcionar o prazer e também a vergonha masculina diante da potência avassaladora do fascínio. Ao pensarmos a dama conquistadora e as gradações entre o jogo erótico, podemos retomar as obras literárias abordadas neste ensaio para nos conduzirmos ao fim, tecendo algumas considerações.

É possível constatar o vigor da imagem perversa e sexual conferida à pessoa de Carlota e como permaneceu impregnada no imaginário literário ao ler as palavras do próprio biógrafo de Blanes, Salterain y Herrera que afirma: "a atración pelo abismo en retrato de doña Carlota Ferreira, decorada de rosas " (SALTERAIN y HERRERA, 1950, p. 230). Entretanto a obra de Larreta parece prever caminhos alternativos, em relação ao pesado fardo da culpa que a memória social insistiu em dedicar aos ombros de Carlota. Apesar de tanto em O guante quanto em Nuestra Señora de los Ramos haver a acentuação da carga sexual dos personagens, ainda assim ele parece efetuar uma guinada contrária, a da mortificação do pintor diante da megera destruidora de lares, ao incluir Carlota como elemento constitutivo do drama familiar. Larreta concebe Carlota 
como a faísca que incendiaria uma atmosfera anteriormente combustiva permeada pelo gás das relações de poder entre os homens da casa.

Ele parece eximir a mulher da carga diabólica que lhe é atribuída ao longo dos anos e a reparte com o ego de Blanes que, nas palavras de Nicanor, é vigoroso e um tanto autoritário. Podemos conceber o fato de que há uma diferença fundamental entre Milton Schinca e Antonio Larreta. O guante é um livro que expõe a relação conflituosa entre pai e filho ao evidenciar que os conflitos internos vivenciados por Nicanor são também fruto da opressão e da cobrança do maestro. Diante do poder opressivo do pai, os meninos teriam criado laços de solidariedade fraternos que provocariam também o distanciamento do filho mais novo com o seu pai. Schinca como Larreta apontam para as personalidades dissonantes entre Blanes e Nicanor, ao deixar com que o pintor declare ao filho que seriam como movimentos distintos: o pai a diástole e o filho a sístole, empregando a imagem de um coração pulsante. O Nicanor de Larreta, em seu desfecho, não perdoa Carlota, porém parece torná-la mais humana e menos diabólica, fugindo das representações construídas. O filho mais velho de Blanes, Juan Luís encontra a morte ao resvalar e cair de um peremptório, o Monte Athos, na Grécia. Tal episódio chocante e inesperado abala uma família atingida pela dor do luto sentido devido à perda de Maria Linari, anos antes.

Larreta, porém confere uma explicação inusitada para o ocorrido. O escritor cria um segredo que seria a relação impossível e incestuosa entre irmãos em um quadrado amoroso inusitado. Em O guante a morte de Juan Luís seria, portanto não um mero acidente, mas uma opção. Impregnado de culpa ocasionada pelo suicídio do irmão Nicanor, escolhe a fuga. No final do livro, antes de fugir para sempre, ele declara ao pai: “No creo que Carlota sea como la pintas, tan intrigante y vengativa” (LARRETA, 2002, p. 160). Larreta, então, parece redimir a culpa que paira em torno de Carlota Ferreira.

Através da leitura de Achugar (2006), sabe-se que Carlota Ferreira foi durante um período a musa de Blanes. Ela contraiu matrimônio com Nicanor e anulou o casamento sem maiores explicações. Juan Luís, o filho mais velho de Blanes morre no estrangeiro e Nicanor corta relações com o pai sumindo definitivamente de sua vida. Os diálogos entre Carlota Ferreira e Blanes, criados por Milton Schinca e o amor incestuoso entre Nicanor e 
Juan Luís são elaborações poéticas das quais não há provas materiais. A partir da leitura de seu testamento epistolar, sabemos que em seus últimos anos de vida, Blanes encontrava-se inconformado e exausto em sua frustrada e intrépida busca no percalço do filho desaparecido Nicanor. Nesse período, suas cartas revelavam a amargura em relação à virada funesta de seu derradeiro destino. O pintor confessou em carta enviada de Florença: "El diablo anda enredando mucho las cosas de este mundo" prevendo o novo século de forma funesta conclui da seguinte forma "el hipócrita se llama hombre de peso, el charlatan, erudito, el romântico se gana la estima de los necios que Le llamarse hábil, y la estima se acuerda por piedad y la consideracion se reserva para los audaces" (BLANES, $18 \mathrm{fev}, 1900)$.

Referente a esse último período, o crítico e biógrafo Salterain y Herrera compara Blanes a Édipo, no bosque sagrado, desmoralizado pelos filhos Polinices e Etéocles, vítima e algoz de seu próprio destino: "no son más oscuras las sombras, ni es más pesado el camino, cuando el cierzo arrecia com fúria, marcando abismos en la frente" (SALTERAIN y HERRERA, 1950, p. 234). Em uma de suas últimas cartas desabafou: “mi país, una terra estraña" (BLANES, $18 \mathrm{dez}, 1900)$.

Verdadeiramente, o pintor nunca conseguiu encontrar o filho. Sobre a pintura de Carlota e o destino do pintor Herrera Mac Lean, declara: “E vagou por cidades e povoados sem encontrar o filho querido, ou quiçá morto. E todo esse hálito de tragédia está oculto neste quadro" (HERRERA Mac Lean, Apud ACHUGAR 2006, p. 264). Blanes morreu em 1901, culpado e desamparado em uma tarde italiana, em Pisa. Carlota Ferreira, após anos de adicção e totalmente insana, falece consumida pelo ópio. O retrato de Blanes sobrevive. Embriagada pelo almíscar e pelo amor, a Vênus platina nos olha e expira em nossos ouvidos o anúncio de sua imortalidade.

\section{Referências}

ACHUGAR, Hugo. Planetas sem boca: escritos efêmeros sobre arte, cultura e literatura. Belo Horizonte: UFMG, 2006. 
APPIGNANESI, Lisa. Tristes, loucas e más: a história das mulheres e seus médicos desde 1800. Rio de Janeiro: Record, 2011

BAUDELAIRE, Charles. Pequenos poemas em prosa. Rio de Janeiro: Record, 2006.

BLANES, Juan Manuel. [Carta] 30 mar.1883, Florença [para] Montevidéu.

Correspondência familiar

BLANES, Juan Manuel. [Carta] 9 jan.1891, Florença [para] Montevidéu. Correspondência familiar.

BLANES, Juan Manuel. [Carta] 18 fev.1900, Florença [para] Montevidéu. Correspondência familiar.

BLANES, Juan Manuel. [Carta] 18 dez.1900, Florença [para] Montevidéu.

Correspondência familiar.

CHEREM, Rosângela; MAKOWIECKY, Sandra. Corpo-paisagem: premeditações para uma história da pintura na América Latina. Florianópolis: UDESC, 2010.

CORBIN, Alain; VIGARELLO, Georges. História do corpo v.2: da Revolução à Grande Guerra. Petrópolis: Vozes, 2009.

DIDI-HUBERMAN, Georges. La pintura encarnada. Valencia: Pre-textos, 2007.

FILÓSTRATO. Amores e outras imagens. São Paulo: Hedra, 2012.

LARRETA, Antonio. El guante. Barcelona: Editorial Planeta, 2002.

LUDMER, Josefina. O corpo do delito: um manual. Belo Horizonte: UFMG, 2002.

KRAMER, Heirnrich; SPRENGER, James. O martelo das feiticeiras: Malleus Maleficarum. Rio de Janeiro: Rosa dos tempos, 2009.

PROSE, Francine. A vida das musas: nove mulheres e os artistas que elas inspiraram. Rio de Janeiro: Nova Fronteira, 2004. 
SALTERAIN Y HERRERA, Eduardo de. Blanes: el hombre, su obra y la época. Montevideo: impresora uruguaya, 1950

SCHINCA, Milton. Mujeres desconocidas: del pasado montevideano. Montevideo: Ediciones de La banda oriental, 1999.

SCHINCA, Milton. Nuestra Señora de los Ramos. Montevideo: Instituto Nacional del libro, 1991.

SOUZA, Fábio Feltrin de: Extremidades da nação: violência, biopolítica e antimodernidade no discurso fundacional da Argentina. 2011, 247f. Tese (Doutorado em História) - Universidade Federal de Santa Catarina, Programa de Pós-Graduação em História. Florianópolis, 2011. 